\title{
Synthesis of MgO Nanoparticles by Solvent Mixed Spray Pyrolysis Technique for Optical Investigation
}

\author{
K. R. Nemade and S. A. Waghuley \\ Department of Physics, Sant Gadge Baba Amravati University, Amravati 444 602, India \\ Correspondence should be addressed to S. A. Waghuley; sandeepwaghuley@sgbau.ac.in
}

Received 27 October 2013; Accepted 30 March 2014; Published 14 April 2014

Academic Editor: Yuanshi Li

Copyright (c) 2014 K. R. Nemade and S. A. Waghuley. This is an open access article distributed under the Creative Commons Attribution License, which permits unrestricted use, distribution, and reproduction in any medium, provided the original work is properly cited.

\begin{abstract}
Solvent mixed spray pyrolysis technique has attracted a global interest in the synthesis of nanomaterials since reactions can be run in liquid state without further heating. Magnesium oxide $(\mathrm{MgO})$ is a category of the practical semiconductor metal oxides, which is extensively used as catalyst and optical material. In the present study, $\mathrm{MgO}$ nanoparticles were successfully synthesized using a solvent mixed spray pyrolysis. The X-ray diffraction pattern confirmed the formation of $\mathrm{MgO}$ phase with an excellent crystalline structure. Debye-Scherrer equation is used for the determination of particle size, which was found to be $9.2 \mathrm{~nm}$. Tunneling electron microscope analysis indicated that the as-synthesized particles are nanoparticles with an average particle size of $9 \mathrm{~nm}$. Meanwhile, the ultraviolet-visible spectroscopy of the resulting product was evaluated to study its optical property via measurement of the band gap energy value.
\end{abstract}

\section{Introduction}

In last two decades, synthesis of metal oxide nanoparticles has attracted considerable attention $[1,2]$. Abundant techniques have been also developed to prepare nanoparticles of $\mathrm{MgO}$. This nanoparticle has attracted much attention due to its wide band gap [3]. However, most of the techniques need high temperatures and perform under a costly inert atmosphere. Kaviyarasu and Devarajan reported a versatile route to synthesize $\mathrm{MgO}$ nanoparticles by combustion technique [4]. Lange and Obendorf studied the effect of plasma etching on destructive adsorption properties of polypropylene fibres containing magnesium oxide nanoparticles [5]. Jin and $\mathrm{He}$ demonstrated antibacterial activities of $\mathrm{MgO}$ nanoparticles against food borne pathogens [6]. Mirzaei and Davoodnia reported the microwave assisted sol-gel synthesis of $\mathrm{MgO}$ nanoparticles and their catalytic activity in the synthesis of Hantzsch 1,4-dihydropyridines [7]. Camtakan et al. studied the uranium sorption properties of $\mathrm{MgO}$ [8].

For the present work, solvent mixed spray pyrolysis method was undertaken to prepare $\mathrm{MgO}$ nanoparticles.
To the best of our knowledge, no report is present in the literature of material science on optical study of $\mathrm{MgO}$ nanoparticles synthesized by solvent mixed spray pyrolysis method. Assynthesized $\mathrm{MgO}$ nanoparticles were characterized by X-ray diffraction (XRD), transmission electron microscopy (TEM), and ultraviolet-visible (UV-VIS) spectroscopy.

\section{Experimental}

All the reagents were of analytical grade and they were used without further purification. MgO nanoparticles were prepared via quick precipitation route using magnesium nitrate $\left(\mathrm{Mg}\left(\mathrm{NO}_{3}\right)_{2} \cdot 6 \mathrm{H}_{2} \mathrm{O}\right)$ and hexamethylenetetramine $\left(\mathrm{C}_{6} \mathrm{H}_{12} \mathrm{~N}_{4}\right)$. In the typical procedure, a stock solution of $1 \mathrm{M}$ solution of $\mathrm{C}_{6} \mathrm{H}_{12} \mathrm{~N}_{4}$ was prepared by dissolving suitable quantity in distilled water. Similarly $1 \mathrm{M} \mathrm{Mg}\left(\mathrm{NO}_{3}\right)_{2} \cdot 6 \mathrm{H}_{2} \mathrm{O}$ solution was prepared by dissolving in distilled water. Both solutions were mixed under magnetic stirring for $10 \mathrm{~min}$ at room temperature. After this procedure, prepared solution was loaded in chamber of spray pyrolysis. The reaction unit 


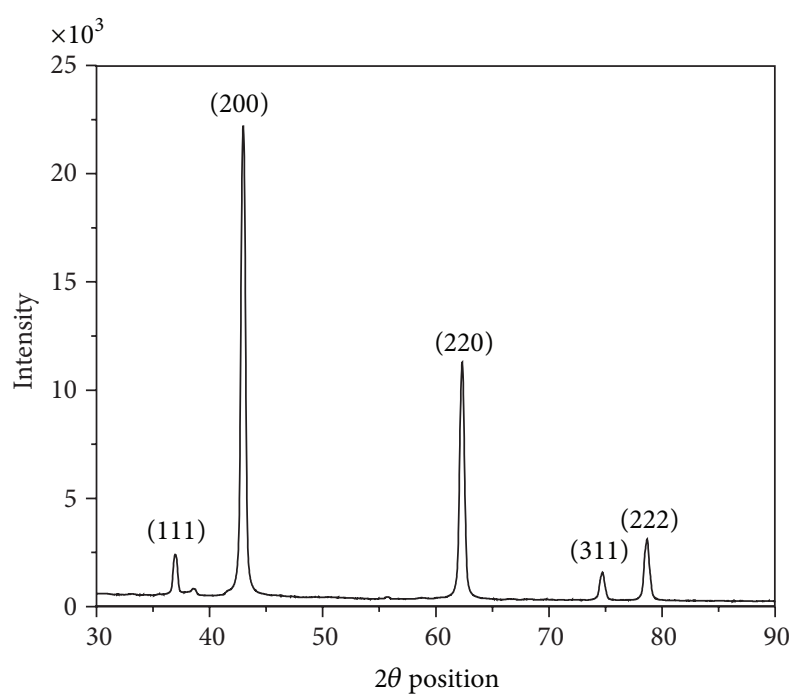

FIGURE 1: XRD pattern of the resulting MgO nanoparticles.

was a flame-spray apparatus consisting of high pressure gas assisted nozzle, which is made of a capillary tube with an outer diameter of $1 \mathrm{~mm}$ (inner diameter $0.6 \mathrm{~mm}$ ) and an opening of $1.2 \mathrm{~mm}$ in diameter. The spray was evaporated by a supporting flamelets maintained at $573 \mathrm{~K}$. The flow rate of the dispersion of solution was controlled by a flow controller. The product was collected on $\mathrm{SiO}_{2}$ substrate. The prepared sample was characterized by X-ray diffraction (XRD), transmission electron microscopy, (TEM) and ultravioletvisible (UV-VIS) spectroscopy. X-ray diffraction pattern was recorded using a Rigaku miniflex-II diffractometer with $\mathrm{CuK} \alpha$ radiation in the range $30^{\circ}-90^{\circ}$. The morphology and grain size of the sample was observed by using TEM (JEOL-1200ex). UV-VIS spectrum was recorded on Perkin Elmer UV spectrophotometer in the range $200-1100 \mathrm{~nm}$ in solution of $\mathrm{MgO}$ nanoparticles dispersed in double distilled water.

\section{Results and Discussion}

The XRD pattern of the final product is shown in Figure 1. This pattern clearly confirmed the presence of the MgO cubic phase with a lattice parameter of $a=b=c=4.213 \AA$ and space group (Fm-3m (225)). The diffraction peaks at $2 \theta$ values of $36.94^{\circ}, 42.90^{\circ}, 62.30^{\circ}, 74.67^{\circ}$, and $78.61^{\circ}$ matching the cubic MgO (PDF- 00-004-0829) indicated the formation of this compound (Figure 2). No other peaks for impurities were detected. The average crystallite size was calculated from diffraction peaks using the Debye-Scherrer equation, which was found to be $9.2 \mathrm{~nm}$ [9].

Figure 3 reveals the TEM images of the obtained $\mathrm{MgO}$ nanoparticles. This image illustrates that small amount of agglomeration is present in the as-synthesized sample. The average crystallite size seen in the micrograph is of the order of $9 \mathrm{~nm}$. Both XRD and TEM analyses of samples are in concurrence with each other.

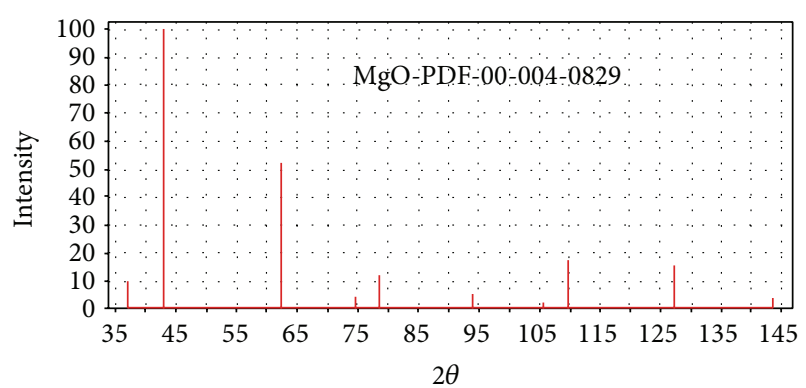

Figure 2: PDF card of MgO.

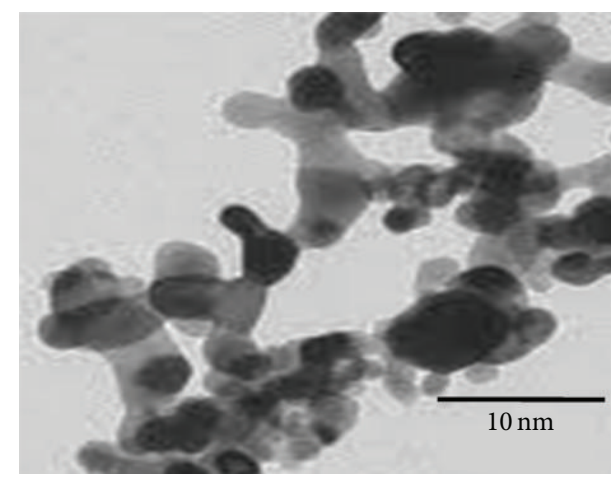

FIgURE 3: TEM images of the resulting MgO nanoparticles.

Figure 4 shows the UV-VIS spectrum of MgO nanoparticles, reflecting variation of \% absorbance of $\mathrm{MgO}$ as a function of wavelength. Broad peak around $203 \mathrm{~nm}$ shows that the particle possesses quantum confinement [10]. This shows that charge particles are confined about three spatial dimensions. The band gap of $\mathrm{MgO}$ nanoparticles was estimated by plotting the $(\alpha h \nu)^{2}$ versus $h \nu(e V)$ as shown in Figure 5. The band gap energy of $\mathrm{MgO}$ nanoparticle was found to be $4.2 \mathrm{eV}$. The value of particle size and band gap of $\mathrm{MgO}$ clearly shows that this nanomaterial is applied in photocatalytic activities and optical devices.

The variation of extinction coefficient with wavelength is shown in Figure 6 . The extinction coefficient $(K)$ is a measure of the fraction of light lost due to scattering and absorption per unit distance of the penetration medium. The extinction coefficient is computed in the sample during the exposure of UV spectra by using the relation between \% absorption and wavelength [11]. Extinction coefficient $(K)$ is as shown in (1):

$$
K=\frac{\alpha \lambda}{4 \pi}
$$

where $\alpha$ is $\%$ absorption and $\lambda$ is wavelength. The curve of extinction coefficient clearly shows that scattering increases gradually from $400 \mathrm{~nm}$ up to $1100 \mathrm{~nm}$ for constant distance of the penetration medium.

The optical reaction of a material is mainly studied in terms of the optical conductivity $(\sigma)$ which is given by the relation (2) [12]

$$
\sigma=\frac{\alpha n c}{4 \pi}
$$




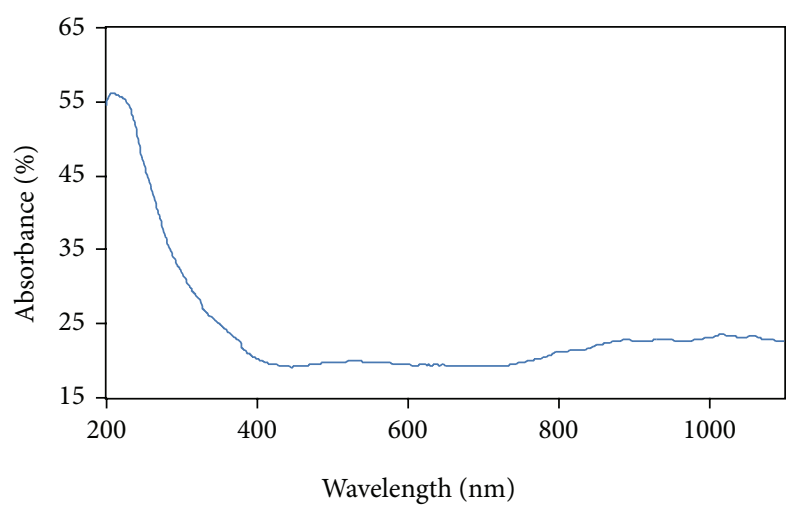

FIgURE 4: UV-VIS of MgO nanoparticles.

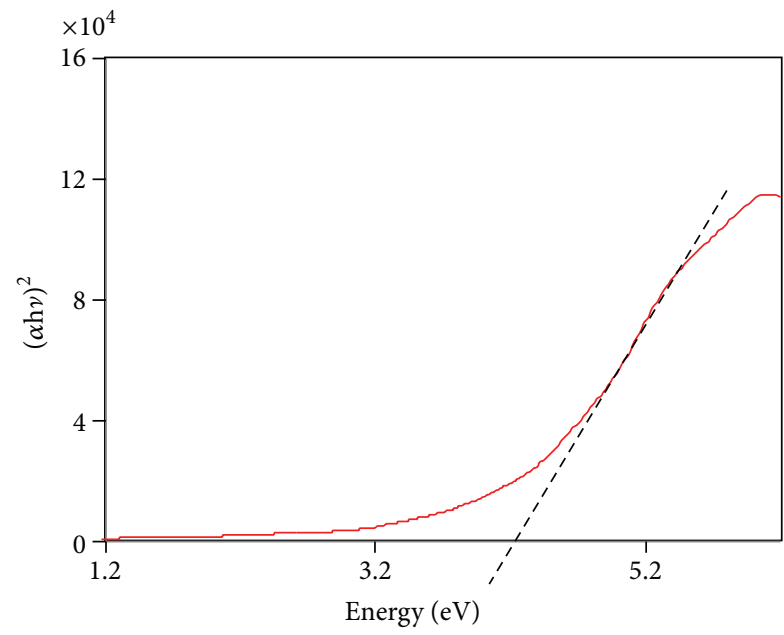

Figure 5: Plot of $(\alpha \mathrm{h} v)^{2}$ versus (h $\left.\nu\right)$ of MgO nanoparticles.

where $c$ is the velocity of light, $\alpha$ is the absorption coefficient, and $n$ is the refractive index. It can be seen clearly from Figure 7 that optical conductivity directly depends on the absorption coefficient and the refractive index of the material. It can be noticed that optical conductivity increases abruptly between 200 and $400 \mathrm{~nm}$. The sudden increase in optical conductivity can be attributed to the decrease in absorption coefficient.

The real and imaginary dielectric constant is a fundamental property of the material. The real and the imaginary parts of the dielectric constant can be estimated using the relations (3) [12]

$$
\varepsilon_{r}=n^{2}-K^{2}, \quad \varepsilon_{i}=2 n K .
$$

The real part of the dielectric constant is to measure how much it will slow down the speed of light in the material. Figure 8 shows that variation of real dielectric constant as a function of photon energy. While the imaginary dielectric constant part shows how a dielectric material absorbs energy from an electric field due to dipole motion, Figure 9 shows the variation of imaginary dielectric constant as a function of photon energy.

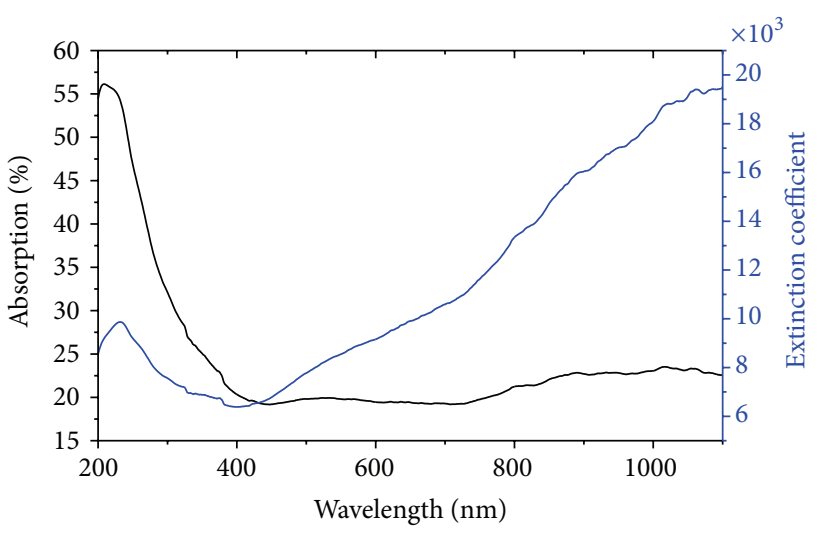

FIGURE 6: Variation of \% absorbance and extinction coefficient of $\mathrm{MgO}$ nanoparticles as a function of wavelength.

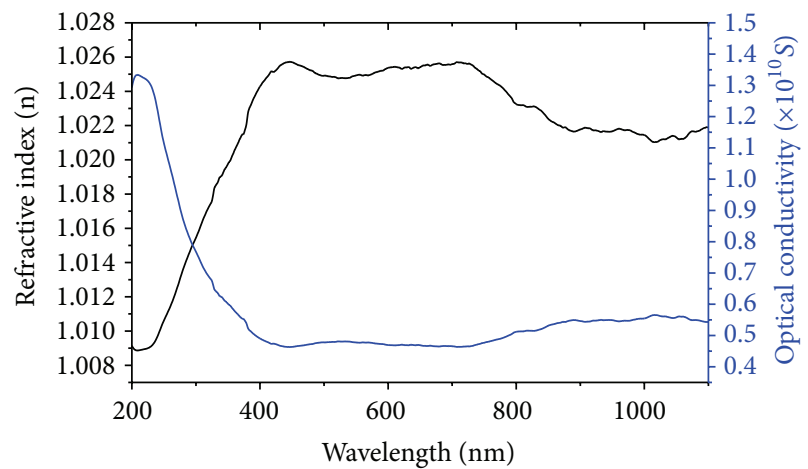

FIGURE 7: Variation of refractive index and optical conductivity of $\mathrm{MgO}$ nanoparticles as a function of wavelength.

\section{Conclusions}

In summary, nanoparticles of $\mathrm{MgO}$ were synthesized using a solvent mixed spray pyrolysis technique. This product was obtained by using $\mathrm{Mg}\left(\mathrm{NO}_{3}\right)_{2} \cdot 6 \mathrm{H}_{2} \mathrm{O}$ and $\mathrm{C}_{6} \mathrm{H}_{12} \mathrm{~N}_{4}$ as starting materials. An average particle size of the resulting nanoparticles was found to be $9 \mathrm{~nm}$ computed using XRD and TEM analyses. The optical property of the produced nanoparticles was studied by measuring the $\%$ absorbance and band gap energy. The estimated optical band gap energy is an accepted value for the photocatalytic activities in visible light and also for application in the solar cells and optical devices. The solvent mixed spray pyrolysis technique used in this study is a simple, useful, and an economic technique to prepare $\mathrm{MgO}$ nanoparticles.

\section{Conflict of Interests}

The authors declare that there is no conflict of interests regarding the publication of this paper. 


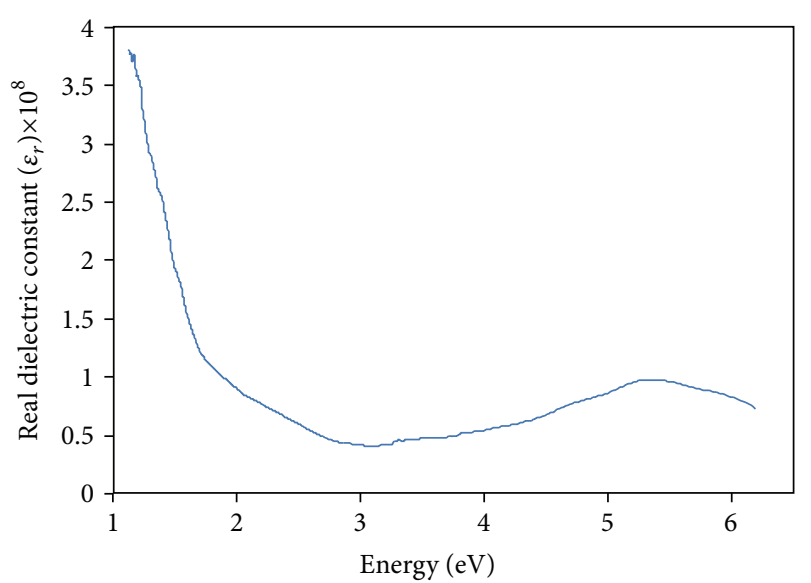

FIGURE 8: Variation of real dielectric constant as a function of photon energy.

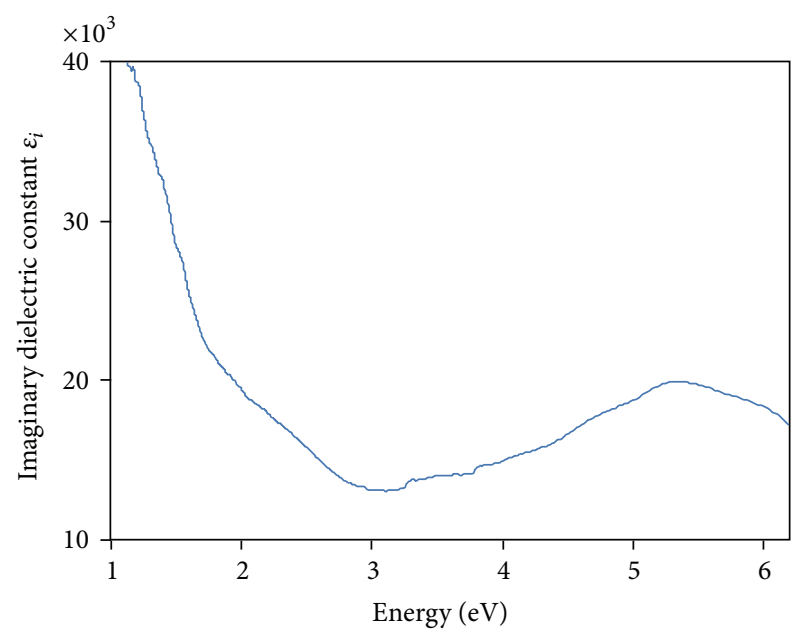

FIGURE 9: Variation of imaginary dielectric constant as a function of photon energy.

\section{Acknowledgment}

The authors are thankful to the Head of the Department of Physics, Sant Gadge Baba Amravati University, Amravati, for providing necessary facilities.

\section{References}

[1] Y. Q. Huang, L. Meidong, Z. Yike, L. Churong, X. Donglin, and L. Shaobo, "Preparation and properties of $\mathrm{ZnO}$-based ceramic films for low-voltage varistors by novel sol-gel process," Materials Science and Engineering B: Solid-State Materials for Advanced Technology, vol. 86, no. 3, pp. 232-236, 2001.

[2] F. Nastase, I. Stamatin, C. Nastase, D. Mihaiescu, and A. Moldovan, "Synthesis and characterization of $\mathrm{PAni}_{-} \mathrm{SiO}_{2}$ and PTh- $\mathrm{SiO}_{2}$ nanocomposites' thin films by plasma polymerization," Progress in Solid State Chemistry, vol. 34, no. 2-4, pp. 191199, 2006.
[3] L. de Matteis, L. Custardoy, R. Fernandez-Pacheco et al., "Ultrathin $\mathrm{MgO}$ coating of superparamagnetic magnetite nanoparticles by combined coprecipitation and sol-gel synthesis," Chemistry of Materials, vol. 24, no. 3, pp. 451-456, 2012.

[4] K. Kaviyarasu and P. A. Devarajan, "A versatile route to synthesize $\mathrm{MgO}$ nanocrystals by combustion technique," Der Pharma Chemica, vol. 3, no. 5, pp. 248-254, 2011.

[5] L. E. Lange and S. K. Obendorf, "Effect of plasma etching on destructive adsorption properties of polypropylene fibers containing magnesium oxide nanoparticles," Archives of Environmental Contamination and Toxicology, vol. 62, no. 2, pp. 185194, 2012

[6] T. Jin and Y. He, "Antibacterial activities of magnesium oxide $(\mathrm{MgO})$ nanoparticles against foodborne pathogens," Journal of Nanoparticle Research, vol. 13, no. 12, pp. 6877-6885, 2011.

[7] H. Mirzaei and A. Davoodnia, "Microwave assisted sol-gel synthesis of $\mathrm{MgO}$ nanoparticles and their catalytic activity in the synthesis of hantzsch 1,4-dihydropyridines," Chinese Journal of Catalysis, vol. 33, no. 9-10, pp. 1502-1507, 2012.

[8] Z. Camtakan, S. Erenturk, and S. Yusan, "Magnesium oxide nanoparticles: preparation, characterization, and uranium sorption properties," Environmental Progress and Sustainable Energy, vol. 31, no. 4, pp. 536-543, 2012.

[9] K. R. Nemade and S. A. Waghuley, "LPG sensing application of graphene $/ \mathrm{CeO}_{2}$ quantum dots composite," in Proceedings of the AIP International Conference on Recent Trends in Applied Physics and Material Science (RAM '13), vol. 1536, pp. 1258-1259, Rajasthan, India, 2013.

[10] K. R. Nemade and S. A. Waghuley, "UV-VIS spectroscopic study of one pot synthesized strontium oxide quantum dots," Results in Physics, vol. 3, pp. 52-54, 2013.

[11] N. A. Bakr, A. M. Funde, V. S. Waman et al., "Determination of the optical parameters of a-Si:H thin films deposited by hot wire-chemical vapour deposition technique using transmission spectrum only," Pramana: Journal of Physics, vol. 76, no. 3, pp. 519-531, 2011.

[12] P. Sharma and S. C. Katyal, "Determination of optical parameters of a- $\left(\mathrm{As}_{2} \mathrm{Se}_{3}\right)_{90} \mathrm{Ge}_{10}$ thin film," Journal of Physics D: Applied Physics, vol. 40, no. 7, article 038, pp. 2115-2120, 2007. 

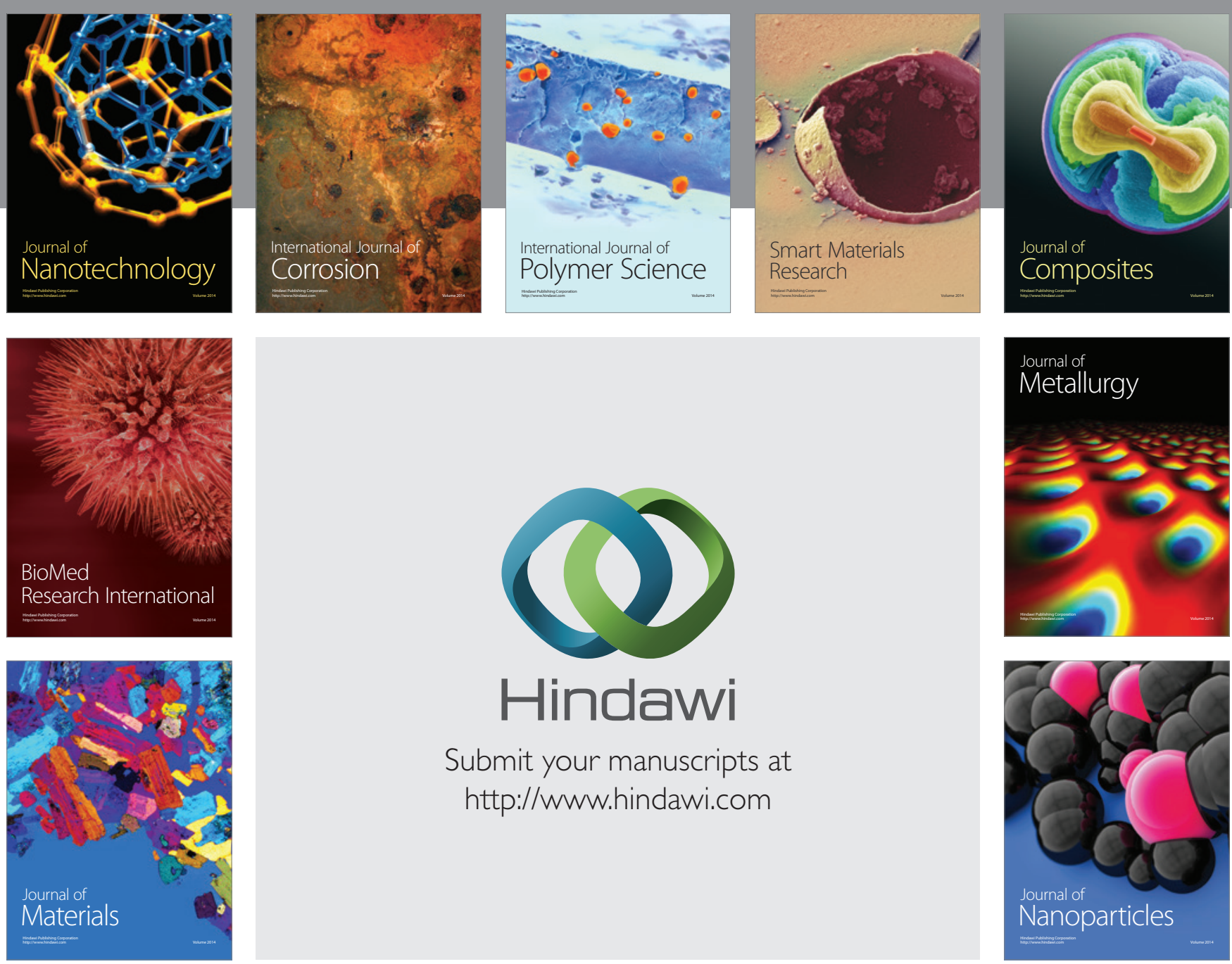

Submit your manuscripts at http://www.hindawi.com
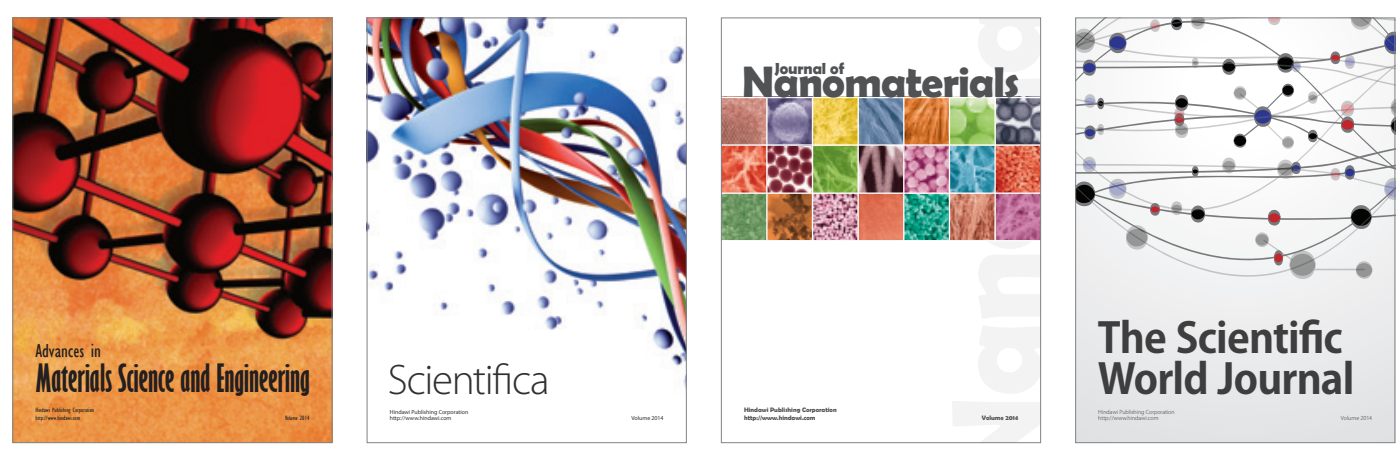

\section{The Scientific World Journal}
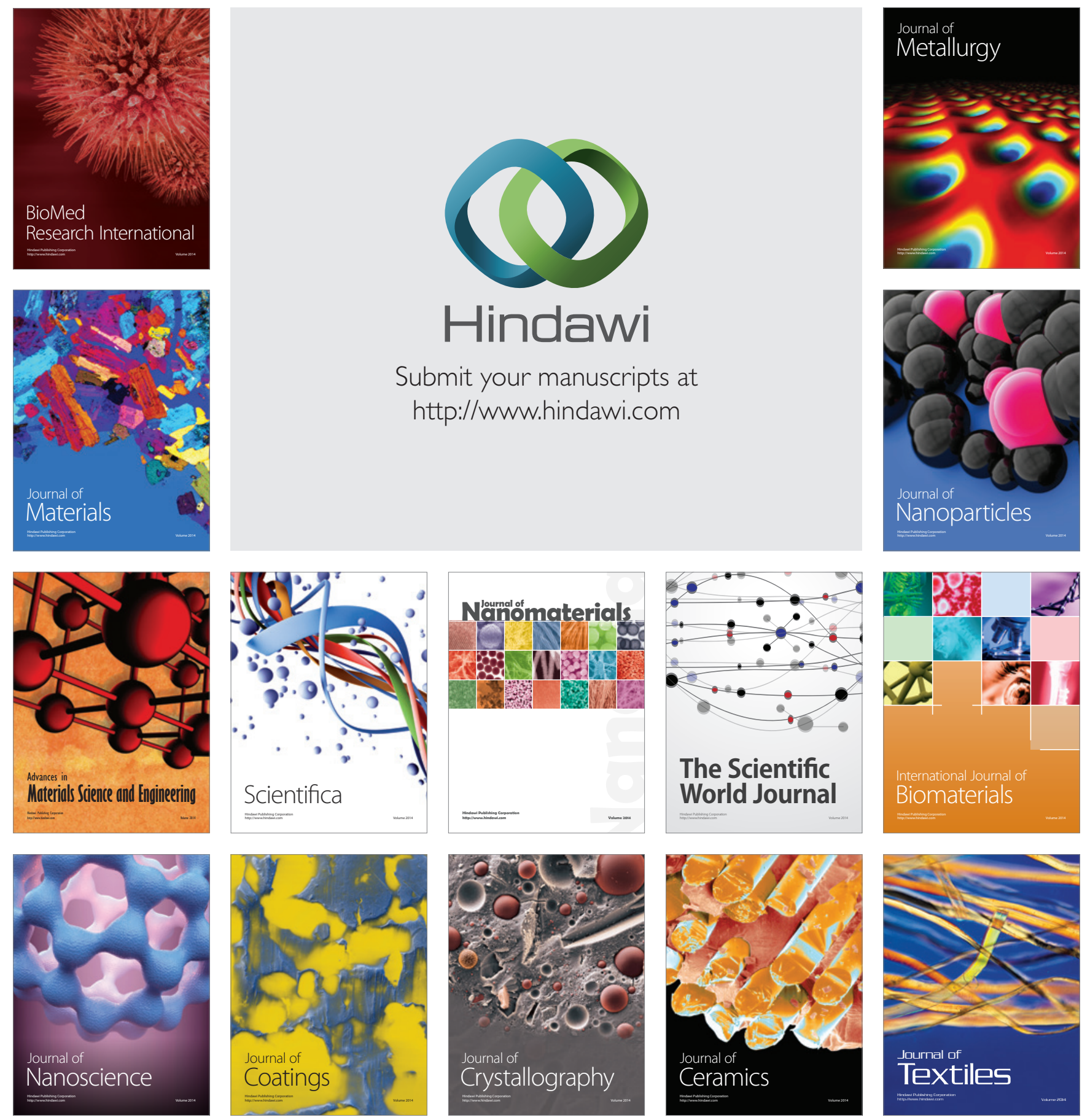